\section{(2) OPEN ACCESS}

\title{
Patient-reported outcome measures (PROMs) as proof of treatment efficacy
}

\section{Stefan Kluzek, ${ }^{1}$ Benjamin Dean, ${ }^{2}$ Karolina A Wartolowska}

10.1136/bmjebm-2020-111573

${ }^{1}$ Centre for Sport, Exercise and Osteoarthritis Research Versus Arthritis, University of Nottingham, Nottingham, UK ${ }^{2}$ Nuffield Department of Orthopaedics, Rheumatology and Musculoskeletal Sciences, Oxford University, Oxford, UK

${ }^{3}$ Nuffield Department of Clinical Neurosciences, Oxford University, Oxford, UK

Correspondence to: Dr Stefan Kluzek, Centre for Sport, Exercise and Osteoarthritis Research Versus Arthritis, University of Nottingham, Nottingham, Nottinghamshire, UK; stefan. kluzek@nottingham.ac.uk
D Check for updates

- Author(s) (or their employer(s)) 2022. Re-use permitted under CC BY-NC. No commercial re-use. See rights and permissions. Published by BMJ.

To cite: Kluzek S, Dean B, Wartolowska KA. BMJ

Evidence-Based Medicine 2022;27:153-155.

\section{Introduction}

In recent years, patient-reported outcome measures (PROMs) have become increasingly popular in clinical practice and clinical trials. In this paper, we highlight the need for introducing measures to control for the bias associated with these inherently subjective measures and combining PROMs with objective outcomes, which do not depend on judgement, experience or performance.

PROMs measure the subjective elements of patients' conditions, including health-related quality of life, pain intensity, activity limitations, participation restrictions, satisfaction or adherence to treatment and help to evaluate the burden of disease and treatment from patients' perspectives. ${ }^{1}$

Originally, PROMs were used in pharmacological research to assess treatment effects in conditions such as cancer, in cases where the cure was not possible, and quality of life became the primary concern. ${ }^{2}$ In the last 20 years, the use of PROMs has increased considerably, ${ }^{13}$ and, currently, those outcomes are used to assess the effects of treatment and quality of care ${ }^{2}$ and to evaluate policies $^{3}$ and to inform health economics. ${ }^{4}$ One of the factors that contributed to the popularity of PROMs was their recognition by the Food and Drug Administration (FDA) and the European Medicines Agency (EMA) as a measure of treatment efficacy. ${ }^{156}$ The FDA and the EMA define PROMs as any outcomes related to the patient's health or treatment that is evaluated directly by the patient, without any interpretation by a doctor or anyone else. ${ }^{16}$ According to this definition, and in contrast to common perception, these outcomes do not necessarily measure what is the most important to patients or health itself. ${ }^{7}$

\section{The role of PROMs}

The main role of PROMs is that they provide important indicators of treatment efficacy not captured by objective markers or clinical assessments. ${ }^{16}$ They may be used as 'red flags' during the assessment of acute symptoms and help to monitor response to treatment, for example, the efficacy of analgesia, especially if they are collected in real time. ${ }^{2}$

Moreover, well-developed PROMs for a specific condition may measure treatment effects on many domains, which is useful because treatment may have a different effect on disease-specific outcomes, health status and quality of life. ${ }^{9}$ Finally, reporting PROMs improves communication between the patient and the care provider and, in turn, increases patient's satisfaction with treatment ${ }^{2}$ and, subsequently, helps with adherence to the treatment itself and with patient retention. ${ }^{10}$

\section{Considerations for the use of PROMs}

Potential limitations and biases associated with PROMs are rarely acknowledged, ${ }^{2} 3511$ although both EMA and FDA recognise that PROMs may not be suitable as primary outcomes in openlabel settings and that they should be supported by objective or functional outcomes. ${ }^{1}{ }^{6}$ By the nature of being subjective, PROMs may be affected by internal factors, such as mood, expectations, time and sentiments, and external factors such as treatment context, interactions with the healthcare providers and patients' socioeconomic situation, which leads to fluctuations in the outcomes. In trials, in which only patients with particularly severe symptoms and disability are recruited, this variability is higher, and PROMs' fluctuations associated with natural regression to the mean might be interpreted as a treatment effect. ${ }^{12}$ Regression towards the mean after a different period of time from the end of each intervention might inflate type 1 error. However, some interventions take longer to work, and their effects may become apparent only after some time causing type 2 error.

Apart from being subjective, some PROMs also require patients to make a judgement regarding the treatment effects. Patients often overestimate benefits and underestimate the risks of treatments. ${ }^{13}$ Under prospect theory, the value is assigned to gains and losses rather than to final assets, and those values depend on experience. This has profound implications for comparison of the efficacy, especially if one treatment arm is associated with an initial deterioration in function, for example, an operation or chemotherapy, followed by a fairly steady recovery, and can provide an overall perception of significant gain, known as the 'rebound' effect (figure 1). Moreover, patients are not necessarily able to identify an improvement in their own health. For example, the improvement measured using the maximum forced expiratory volume in $1 \mathrm{~s}$ in patients with asthma may not translate into a positive change in terms of patientreported improvements when compared with placebo. ${ }^{14}$ Therefore, it is important to combine PROMs with functional outcomes in order to gain insight into both physiological effect and patients' well-being. Similarly, what patients report as important may not be what they 


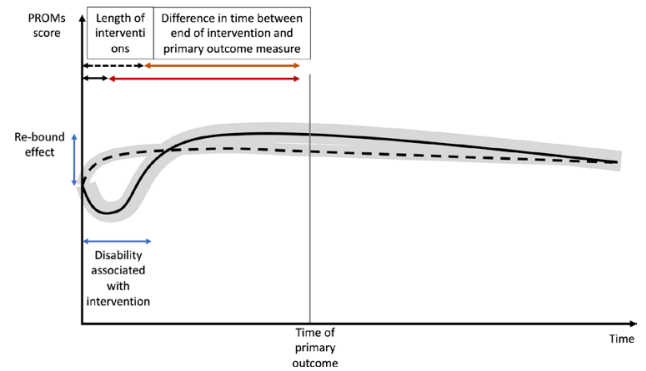

Figure 1 Change in PROMs with time and the 'rebound' effect. PROMs, patient-reported outcome measures.

actually choose. For example, patients often say that pain relief is the most important for them, but many do not take some of their pain killers and are willing to accept some level of pain in order to be able to function and they do not actually expect to be pain free. ${ }^{15}$ These examples demonstrate that the assessment of treatment efficacy requires careful and multidimensional approach based on PROMs and functional outcome measures.

PROMs may be able to capture multiple domains, but the drawback of using PROMs with a broad outcome set is the tendency for patients to report only some of them. Selective reporting is a common problem despite reporting guidelines and clinical trial registries. ${ }^{16}$ However, a narrow set of outcomes increases the risk of missing clinically meaningful changes. Finally, due to variability, PROMs measurements are often categorised, which reduces reliability and decreases power. ${ }^{17}$

\section{Strategies to improve the use of PROMs}

In open-label settings, patients are likely to exaggerate the treatment effect, especially if the treatment is invasive. ${ }^{18} 1819$ Blinding of patients reduces reporting bias as well as a risk of unbalanced attrition or cointerventions, ${ }^{18}$ and blinding of doctors or researches reduces observer's and detection bias; however, biases related to unblinded patients tend to be larger than those caused by unblinded assessors. ${ }^{19}{ }^{20}$ When blinding is not possible, PROMs collection should be combined with functional, imaging and biochemical biomarkers adding an element of objectivity. ${ }^{16}$

The treatment effect should improve patients' satisfaction and surpass the placebo effect; therefore, when it is important to assess the magnitude of improvement or harms associated with an active intervention, a placebo-controlled randomised controlled trial (RCT) may be necessary. ${ }^{21}$

The variability of PROMs can be mitigated by collecting measurements at multiple time points to assess the trajectories of symptoms' progression and recovery. This approach has several benefits: it reduces the bias caused by the patient having a 'bad day', provides information about disease trajectories and treatment effects over time and helps to identify participants with similar patterns. ${ }^{22}$

\section{Conclusions}

PROMs provide evidence on the effect of interventions on patient symptoms and quality of life, but by the nature of being subjective, they are prone to bias. Blinded RCTs, preferably with a placebo control, are crucial if the evidence of efficacy is to be based on PROMs. Furthermore, collecting multiple PROMS over time as "progression trajectories" may help to overcome the single measure variability. Finally, PROMs should be used in conjunction with objective outcomes, especially when assessment by blinded clinicians or researchers is not possible.

Twitter Karolina A Wartolowska @KAWartolowska

Acknowledgements This work has been supported by Versus Arthritis Centre for Sport, Exercise and Osteoarthritis Research.

Collaborators There are no other collaborators. All researchers involved in this manuscript are named as its authors.

Contributors KAW conceived the idea for the manuscript and wrote the manuscript. SK wrote the manuscript and created the figure. All authors edited the manuscript and revised it critically for important intellectual content. All authors read and approved the final manuscript.

Funding The authors have not declared a specific grant for this research from any funding agency in the public, commercial or not-for-profit sectors.

Competing interests None declared.

Patient consent for publication Not required.

Provenance and peer review Not commissioned; externally peer reviewed.

Open access This is an open access article distributed in accordance with the Creative Commons Attribution Non Commercial (CC BY-NC 4.0) license, which permits others to distribute, remix, adapt, build upon this work non-commercially, and license their derivative works on different terms, provided the original work is properly cited, appropriate credit is given, any changes made indicated, and the use is non-commercial. See: http://creativecommons.org/licenses/by-nc/4.0/.

\section{ORCID iD}

Karolina A Wartolowska http://orcid.org/0000-0003-4049-2364

\section{References}

1 Allik H, Larsson J-0, Smedje H. Guidance for industry: patient-reported outcome measures: use in medical product development to support labeling claims: draft guidance. Health Qual Life Outcomes 2006;4:1-20. doi:10.1186/1477-7525-4-1

2 Chen J, Ou L, Hollis SJ. A systematic review of the impact of routine collection of patient reported outcome measures on patients, providers and health organisations in an oncologic setting. BMC Health Serv Res 2013;13:1.

3 Black N. Patient reported outcome measures could help transform healthcare. BMJ 2013;346:f167-5.

4 Rolfson 0, Kärrholm J, Dahlberg LE, et al. Patient-reported outcomes in the Swedish hip arthroplasty register: results of a nationwide prospective observational study. J Bone Joint Surg Br 2011;93:867-75.

5 Bottomley A, Jones D, Claassens L. Patient-Reported outcomes: assessment and current perspectives of the guidelines of the food and drug administration and the reflection paper of the European medicines Agency. Eur J Cancer 2009;45:347-53.

6 European Medicines Agency, Committee for Medicinal Products for Human Use (CHMP). Appendix 2 to the Guideline on the evaluation of anticancer medicinal products in man. The use of patient-reported outcome (pro) measures in oncology studies, 2016. https://www.ema.europa.eu/en/ documents/other/appendix-2-guideline-evaluation-anticancer-medicinalproducts-man_en.pdf

7 Trujols J, Portella MJ, Iraurgi I, et al. Patient-Reported outcome measures: are they patient-generated, patient-centred or patient-valued? J Ment Health 2013;22:555-62.

8 Ware JE. Measuring patients' views: the optimum outcome measure. SF36: a valid, reliable assessment of health from the patient's point of view. BMJ 1993;306:1429-30. 
9 Bradley C, Eschwège E, de Pablos-Velasco P, et al. Predictors of quality of life and other patient-reported outcomes in the Panorama multinational study of people with type 2 diabetes. Diabetes Care 2018;41:267-76.

10 Wartolowska $\mathrm{K}$. The nocebo effect as a source of bias in the assessment of treatment effects. F1000Res 2019;8:5.

11 Smith S, Weldring T. Patient-Reported outcomes (pros) and patientreported outcome measures (PROMs). Health Services Insights 2013;61.

12 Hengartner MP. Is there a genuine placebo effect in acute depression treatments? A reassessment of regression to the mean and spontaneous remission. BMJ Evid Based Med 2020;25:46-8.

13 Hoffmann TC, Del Mar C. Patients' expectations of the benefits and harms of treatments, screening, and tests: a systematic review. JAMA Intern Med 2015;175:274.

14 Wechsler ME, Kelley JM, Boyd IOE, et al. Active albuterol or placebo, sham acupuncture, or no intervention in asthma. New England Journal of Medicine 2011;365:119-26.

15 Gibbins J, Bhatia R, Forbes K, et al. What do patients with advanced incurable cancer want from the management of their pain? A qualitative study. Palliat Med 2014;28:71-8.

16 Zhang S, Liang F, Li W. Comparison between publicly accessible publications, registries, and protocols of phase III trials indicated persistence of selective outcome reporting. $J$ Clin Epidemiol 2017;91:87-94.

17 Borm GF, Munneke M, Lemmers 0, et al. An efficient test for the analysis of dichotomized variables when the reliability is known. Stat Med 2007;26:3498-510.

18 Hróbjartsson A, Emanuelsson F, Skou Thomsen AS, et al. Bias due to lack of patient blinding in clinical trials. A systematic review of trials randomizing patients to blind and nonblind sub-studies. Int J Epidemiol 2014;43:1272-83.

19 Hróbjartsson A, Thomsen ASS, Emanuelsson F, et al. Observer bias in randomized clinical trials with measurement scale outcomes: a systematic review of trials with both blinded and nonblinded assessors. Can Med Assoc J 2013;185:E201-11.

20 Moustgaard H, Bello S, Miller FG, et al. Subjective and objective outcomes in randomized clinical trials: definitions differed in methods publications and were often absent from trial reports. J Clin Epidemiol 2014;67:1327-34.

21 Wartolowska K, Judge A, Hopewell S, et al. Use of placebo controls in the evaluation of surgery: systematic review. BMJ 2014;348:g3253.

22 Radojčić MR, Arden NK, Yang X, et al. Pain trajectory defines knee osteoarthritis subgroups. Pain 2020;161:2841-51. doi:10.1097/j. pain.0000000000001975 